\title{
Design of an Inverted U-Shaped MIMO Patch Antenna for Dual Band Applications
}

\author{
T.Mohan Krishna ${ }^{1}$, K.Kranth Kiran ${ }^{2}$, K.Prasanth ${ }^{3}$, B.Shivaji Reddy ${ }^{4}$, A.Tathababu \\ Student, St.Ann's College of Engineering \& Technology, Chirala, A.P, India ${ }^{1,2,3,4}$ \\ Assistant Professor, St.Ann's College of Engineering \& Technology, Chirala, A.P, India 5
}

\begin{abstract}
A compact design of two element Multiple Input MultipleOutput (MIMO) system is proposed using an inverted U-shaped patch antenna. The antenna is fed by a coaxial feeding technique printed on a dielectric FR-4 substrate. The proposed MIMO system offers good return loss and isolation characterstics. This two element MIMO system produces dual band of frequencies with resonating frequencies at $2.8 \mathrm{GHz}$ and $6.4 \mathrm{GHz}$, which can be used for WLAN and satellite applications. The simulation results of return loss,mutual coupling and radiation pattern are presented in this paper.
\end{abstract}

Keywords: Inverted U-Shaped, MIMO, Return loss, WLAN,S atellite, Mutual Coupling.

\section{INTRODUCTION}

Now a day's communication system changes into wireless ubiquity which means that every person wants to reach whatever he wants, whenever he wants, wherever he wants and for this we must have broad frequency spectrum. Microstrip antenna is generally used for many wireless applications due to light weight and patch can be of any shape. Patch is generally made of material such as copper or gold. In radar and satellite communication, it is necessary to design antennas with very high directive characteristics to meet the demand of long distance communication and the most common configuration to satisfy this demand is the array form of the Microstrip antenna.

The main objective of MIMO antenna is to reduce the correlation between the received signals among the antenna ports and maximize the channel capacity[1].The correlation between the received signals is mainly due to the mutual coupling of the transmitting MIMO antennas.By calculating the mutual coupling,we can analyze the electromagnetic field interaction which are existed between antenna elements of MIMO systems. The mutual coupling mainly depends on the distance between the antenna elements. The main source for this mutual coupling is studied in [2,3].For the reduction of mutual coupling there are various methods like, using Electronic Band Gap (EBG) structures, defected ground structures, decoupling techniques, etc.

Further, most of the antennas presented in the literature are either complex in their structure or bigger in size and hence require careful manufacturing procedure than that of the regular microstrip antenna for practical applications. In this paper, we have designed a simple inverted U-shaped MIMO antenna [4] to achieve dual band of frequencies resonating at $2.8 \mathrm{GHz}$ and $6.4 \mathrm{GHz}$ with a return loss of $<-10 \mathrm{~dB}$. The proposed antenna may find applications in wireless and satellite communications.

\section{ANTENNA DESIGN}

In this design, microstrip antenna is used due to its light weight, thin size and patch can be of any shape.
MIMO patch microstrip antenna has been selected for this investigation as it is simple in design. The structure of an inverted U-shaped MIMO patch antenna is shown in Fig.1.

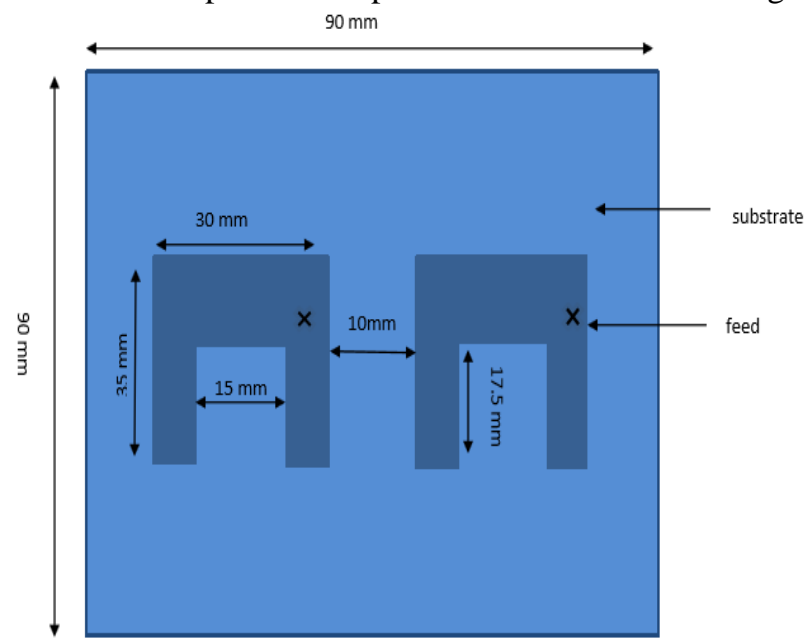

Figure 1: Inverted U-Shaped MIMO Patch Antenna

This antenna is etched on a FR-4 substrate with relative permittivity 4.4 and thickness of $1.8 \mathrm{~mm}$. FR-4 in comparison has a higher dielectric constant which results in a smaller patch size. On the top layer of antenna, there is rectangular shape radiating plane with dimension of $35 \times 30 \mathrm{~mm}$ with U-shaped fractal [5] with dimension of $17.5 \mathrm{~mm} \times 15 \mathrm{~mm}$. On the bottom layer, there is a square shape ground plane with side length of $90 \mathrm{~mm}$. Co-axial feeding technique is used as excitation method.

The two antenna elements are separated by a distance of $10 \mathrm{~mm}$ in this proposed MIMO system. For the proposed antenna we have obtained the dual band of resonating frequencies at $2.8 \mathrm{GHz}$ and $6.4 \mathrm{GHz}$. These frequency bands of operation with less mutual coupling can be used for Wireless LAN, Aeronautical radio navigation at $2.8 \mathrm{GHz}[6]$ and Satellite communications (uplinks) at $6.4 \mathrm{GHz}[7]$. Some of these band frequencies are also used for WiMAX (Wireless interoperability for microwave access) and wireless communications. 
TheS11and $S 21$ results are presented in Fig.2(a) \& 2(b) respectively. From the observed results it is evident that the proposed MIMO antenna exhibits excellent isolation properties $(S 21)$ at the resonant frequencies of $2.8 \mathrm{GHz}$ and $6.4 \mathrm{GHz}$ with better return loss (S11) of -25 $\mathrm{dB}$ and $-27 \mathrm{~dB}$ respectively, which gives good impedance matching for the antenna. $[8,9]$

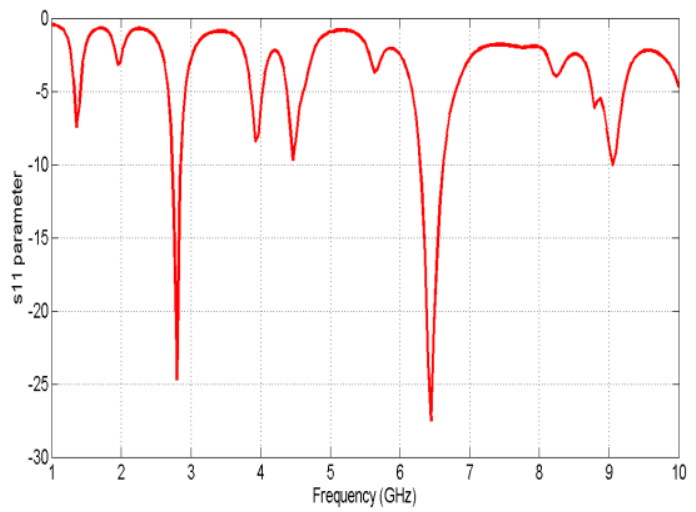

Figure 2(a): S11 Parameters of the Proposed Antenna

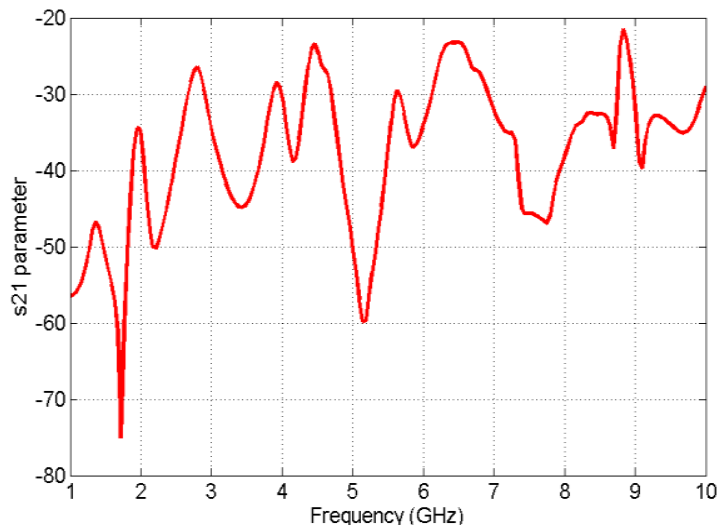

Figure 2(b): S21Parameters of the Proposed Antenna

The VSWR plot of the proposed MIMO array is presented in the Fig.3.The plot gives the desired values of VSWR at the resonant frequency which is less than 2 .

The less VSWR value is observed at the resonant frequencies $2.8 \mathrm{GHz}$ and $6.4 \mathrm{GHz}$, indicating good matching conditions. The radiation pattern of the proposed antenna at the resonant frequencies is as shown in Fig.4(a) $\& 4(b)$

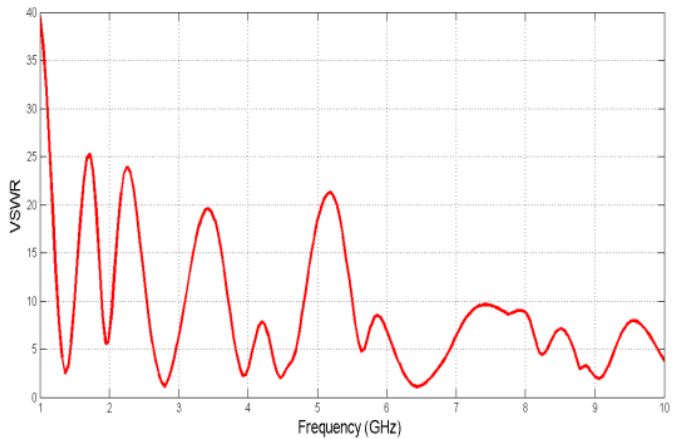

Figure 3: VSWR Plot of the Proposed MIMO Antenna

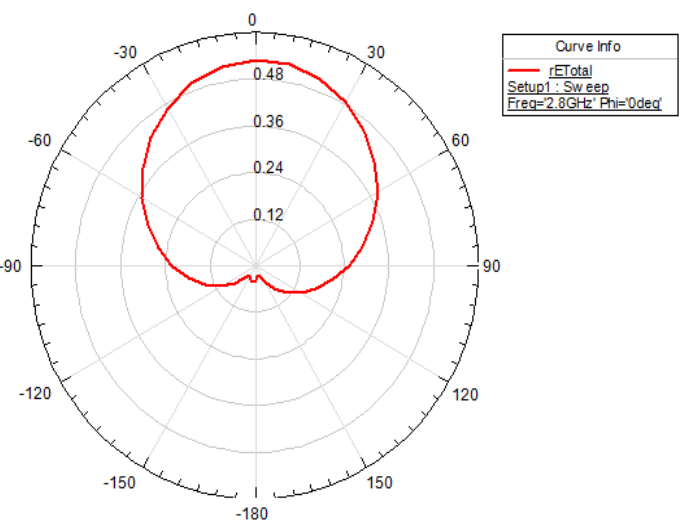

Figure 4(a): Radiation Pattern at $2.8 \mathrm{GHz}$ for $\Phi=0^{0}$

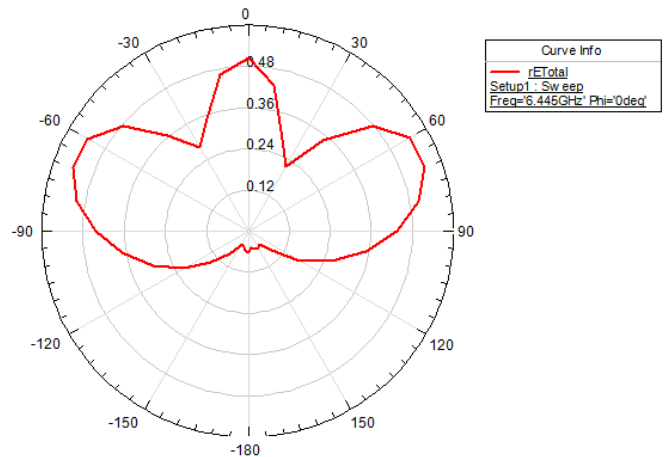

Figure 4(b):Radiation Pattern at $6.44 \mathrm{GHz}$ for $\Phi=0^{0}$

The 3D polar plot of proposed MIMO antenna is shown in figure 5.
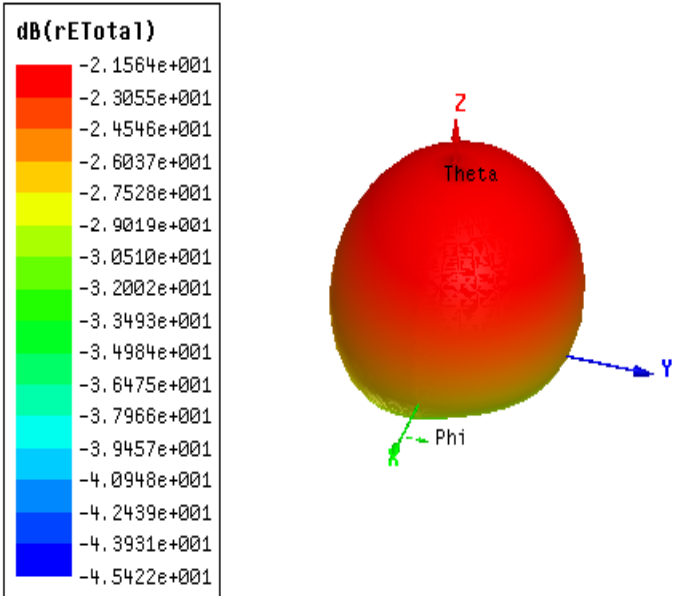

Figure 5: 3D Polar Plot of Proposed MIMO Antenna

\section{CONCLUSION}

A good design of antenna can improve the performance of the system. In this paper we have proposed an inverted U-shaped MIMO patch antenna which produces dual band of frequencies resonates at $2.8 \mathrm{GHz}$ and $6.4 \mathrm{GHz}$ with excellent return loss of $<-25 \mathrm{~dB}$. Hence from the above results we can conclude that this MIMO antenna is well suited for wireless(WLAN) and satellite communications. 


\section{REFERENCES}

[1] A. A. Abouda and S. G. Hagagman. Effect of mutual coupling capacity of MIMO wireless channels in high SNR scenario. Progress in Electromagnetics Research, 65(2006)1, 27-40.

[2] D. E. J. Humphrey and V. F. Fusco. A mutual coupling model for microstrip patch antenna pairs with arbitrary orientation. Microwave and Optical Technology Letters, 18(1998)3, 230-233.

[3] M. M. Nikolic, A. R. Djordevic, and A. Nehorai. Microstrip antennas with suppressed radiation in horizontal directions and reduced Coupling. IEEE Transactions on Antennas and Propagation, 53(2005) 11, 3469-3476.

[4] Weig, S., G. H. Hu®, K. H. Pan, and J. T. Bernard, \Analysis and design of broadband single layer U-slot microstrip patch antennas," IEEE Transactions on Antennas and Propagation, Vol. 51, No. 3, $457\{468$, March 2003.

[5] D. H. Werner, R. L. Haupt, and P. L. Wernej, "Fractal Antenna Engineering: The Theory and Design of Fractal Antenna Arrays", IEEE Antenna and Propagation Magazine, pp. 37-57, 1999.

[6] Guruprasad V.Burshe, Sanjay V. Khobragade, Dr.Anitha V.R. Circularly Polarized Microstrip Patch Array for Wireless Communication Applications, 978-1-4244-5118-0/11 2011 IEEE

[7] Neha Ahuja, Rajesh Khanna, Jaswinder Kaur.Dual Band Defected Ground Microstrip Patch Antenna for WLAN/WiMax and Satellite Application,International Journal of Computer Applications (0975 8887), Volume 48- No.22, June 2012.

[8] Cakir, G. and L. Sevgi, IDesign of a novel microstrip electromagnetic band-gap (EBG) structure," Microwave Opt. Technol Lett., Vol. 46, 399\{401, 2005.

[9] K. Jagadeesh Babu, Dr.K.Sri Rama Krishna, Dr.L.Pratap Reddy. A Multi Slot Patch Antenna for 4G MIMO Communications. International Journal of Future Generation Communication and Networking Vol. 4, No. 2, June, 2011.

\section{BIOGRAPHIES}

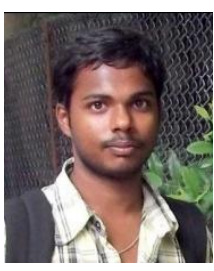

T.Mohan Krishna, pursuing hisB.Tech degree in Electronics \& Communication Engineering in St.Ann's College of Engineering \& Technology, JNTUK. His areas of interest include Antenna Designing \& Communications. He is a member of ISTE.

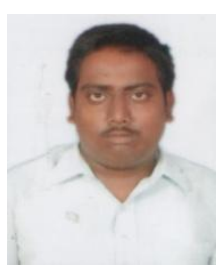

K.Kranth Kiran, pursuing hisB.Tech degree in Electronics \& Communication Engineering in St.Ann's College of Engineering \& Technology, JNTUK. His areas of interest include Antenna Designing \& Communications. $\mathrm{He}$ is a member of ISTE.

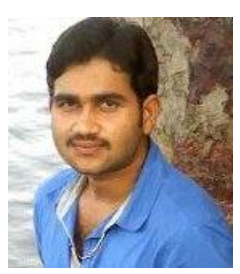

K.prasanth, pursuing hisB.Tech degree in Electronics \& Communication Engineering in St.Ann's College of Engineering \&Technology, JNTUK. His areas of interest include Antenna Designing \& Communications. He is a member of ISTE.

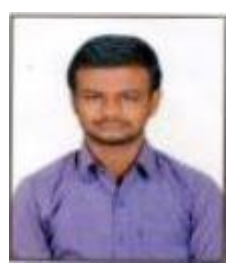

B.Shivaji Reddy,pursuing hisB.Tech degree in Electronics \& Communication Engineering in St.Ann's College of Engineering \& Technology, JNTUK. His areas of interest include Antenna Designing \& Communications. He is a member of ISTE.

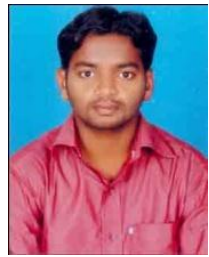

A.Tathababu is working as Asst.Professor in E.C.E Dept., at St.Ann's College of Engineering \& Technology, Chirala, India. He received his B.Tech degree in E.C.E from JNTUH and M.Tech (DECS) degree in E.C.E from JNTUK.His areas of interest include Microwaves,MIMO Antennas, Wireless communications. 